\title{
Chaos: exploring an engaging online model for rapid application during the pandemic
}

\author{
Joshua W. Tabor ${ }^{1}$ (iD \\ Accepted: 6 November 2020 / Published online: 20 November 2020 \\ (c) Association for Educational Communications and Technology 2020
}

\begin{abstract}
This paper is in response to the article entitled "A design framework for enhancing engagement in student-centered learning: own it, learn it, and share it" (Lee and Hannafin 2016). The authors propose a framework that could assist teachers in their transition from face to face classroom settings to a completely digital, student-centered, learning format. The article provides an outline and questions that can be applied to current teaching methodologies but will require ongoing teacher training. The difficulty in applying this outline is a possible lack of understanding of student-centered learning techniques, lack of time to train teachers and, possibly, teacher apathy towards online education. This article provides an adaptable framework schools can use immediately, and the effectiveness of its application should be studied.
\end{abstract}

Keywords Design framework · Online learning $\cdot$ Student-centered $\cdot$ Technology $\cdot$ Virtual learning

\section{Introduction}

Many teachers and administrators achieve advanced degrees using online learning methods; however, many of these same educators often discount the benefits of this learning method (Connolly and Diepenbrock 2011). Online learning practices are seen as being good enough for post-secondary coursework, yet inadequate for K-12 students, which has caused school districts to slow the development of their online learning programs and even dismiss online learning completely.

Due to COVID-19, school districts are now searching for an online course framework that can be universally applied to help their teachers and students succeed. Unfortunately, pivoting to online learning after decades of dismissing it is not as simple as one would hope. It is not enough to simply take traditional learning and move it to a digital learning platform such as Canvas or Google Classroom. There must be intentional planning and preparation, more than needed in a traditional face to face course (Baran et al. 2013).

Joshua W. Tabor

taborslyceum@gmail.com

1 Department of Education, University of North Texas, Denton, TX, USA 
Lee and Hannafin (2016), using constructivist, student-centered theories, have created an online course framework that outlines how schools can adapt their standard curricula to an online format. This framework helps administrators and teachers understand why they need to adjust their lessons and how those changes will prepare them for online teaching. As school districts plan for the upcoming year, they would benefit from allowing their teachers to practice with the framework and setting expectations that some, if not all, of it be followed.

\section{Impact}

Lee and Hannafin's student-centered framework, created following the principles of selfdetermination theory, constructivism, and constructionism, has three steps: own it, learn it, share it (p. 723). 'Own it' attempts to bring in student engagement through students use of self-determination. Students can set their own goals and determine how they will achieve those goals. Once students' goals are set, they move to the, teacher supported, 'learn it' part of the framework. The teachers provide support through direct instruction, providing tools and resources or discourse helping students understand the content behind their chosen goals. Finally, in the 'share it' part of the framework students will show their completed work, ideally a physical artifact, to a selected group. This group will provide feedback allowing students to understand different perspectives and allow them to revisit and re-evaluate their goals. Each step in the framework is designed to provide students the support they need (learn it) as they explore topics interesting to them (own it) with a tangible product that is evaluated upon completion (share it). Not only is this student-centered approach beneficial for creating lifelong learners, it is also particularly important for digital learning (Ryan and Deci 2000; Schneider et al. 2018).

Throughout their paper, the authors compare traditional, direct instruction to student centered digital learning. Engaging students in digital learning requires a different methodology than face to face learning. Lee and Hannafin address the unique needs of students in digital learning programs by enabling them to take their learning into their own hands and thus be more successful. However, for teachers who are used to more control in a physical classroom setting, this can be difficult. Lee and Hannafin provide multiple examples explaining the 'why' of each part of the framework so teachers can fully understand the rationale behind the changes in their methods. Providing teachers with this framework gives them more support in understanding the needs of digital learners and how they can adapt their teaching styles to this new environment.

\section{Application}

Lee and Hannafin's framework can be applied immediately which benefits school districts as a great deal of time will be spent on professional development for shifting the focus from classroom, face to face teaching to online teaching. Teachers should be breaking down the framework together and determining how they can apply it to their online course outlines. When meeting in content areas, teachers should go through their district/campus curriculum plans and align assignments with how they fit within the framework. This will allow teachers a better understanding of how their existing work can migrate into the online setting and how that work will function in a student-centered classroom. In addition, 
teachers should be examining how the framework applies to the learning management system (LMS) their district has chosen as each system has strengths and limitations.

\section{Limitations and constraints}

To apply a new concept, such as Lee and Hannafin's framework, teachers will need proper training. They will need time to focus on the different branches of the own it, learn it, share it framework and how it applies to their newly developed online courses. Unfortunately, many teachers have never been trained, either through education programs or professional development, on how to create effective online learning (Comas-Quinn 2011). This constraint was magnified as schools scrambled to assist teachers in moving their content online. Untrained teachers have difficulty understanding the unique needs of online students (Oberski et al. 1999). For example, in an online situation a student should have more freedom to explore, with assignments focusing on knowledge building, yet many teachers want to give them less freedom and exert more control (Weiner 2003). This need for control is also highlighted by Keengwe and Kidd (2010) in their discussion of issues teachers need to overcome to find success in an online course. However, it highlights how little students are prepared to function without direct guidance from an instructor. Furthermore, this lack of training may cause teachers to not feel confident in digital learning, which may result in teachers being unwilling or resistant to adapting best practices (Baran et al. 2011).

\section{Future suggestions}

The Own it, Learn it, Share it framework has positive potential for many students, yet more research needs to be done on the overall effectiveness on student learning. Assumptions were made during the creation of the framework, such as teachers understanding of student-centered learning environments. Teachers will need proper training on what an effective, student-centered learning environment looks like, then be trained on how to adapt that environment to an online setting. This is no simple task as teachers are overwhelmed with adapting lesson plans to an online format, supporting students' social/emotional needs and learning a wide variety of online educational tools in addition to the stress of possibly becoming infected with COVID-19 (Kozimor 2020).

Studies should be conducted on not only the effectiveness of Lee and Hannafin's framework, but the success of shifting to online, student-centered learning. The COVID-19 pandemic is fundamentally changing how education is delivered and there has never been a better time to record data for future study. Once the pandemic has passed, whatever that new normal looks like, the desire for an online learning option will remain or, possibly, increase. Schools and school districts will need to continue improving their online education methods and course designs which will be done through continuous training and research. Lee and Hannafin have provided a quality framework that any district can adapt to their specific needs and use as a foundation as they move forward.

\section{Compliance with ethical standards}

Conflict of interest There are no potential conflicts of interest in this paper. 
Research involving human and animal rights No human or animal participants were involved in the study or writing of this paper.

Informed consent No informed consent was necessary for this paper.

\section{References}

Baran, E., Correia, A., \& Thompson, A. (2011). Transforming online teaching practice: Critical analysis of the literature on the roles and competencies of online teachers. Distance Education, 32(3), 421-439. https://doi.org/10.1080/01587919.2011.610293.

Baran, E., Correia, A., \& Thompson, A. (2013). Tracing successful online teaching in higher education: Voices of exemplary online teachers. Teachers College Record, 115(3), 1-41.

Comas-Quinn, A. (2011). Learning to teach online or learning to become an online teacher: An exploration of teachers' experiences in a blended learning course. ReCALL, 23(3), 218-232. https://doi. org/10.1017/S0958344011000152.

Connolly, S., \& Diepenbrock, A. (2011). Perspectives of onlin graduate preparation programs for student affairs professionals. The American Journal of Distance Education, 25(2), 79-90.

Keengwe, J., \& Kidd, T. (2010). Towards best practices in online learning and teaching in higher education. MERLOT Journal of Online Learning and Teaching, 6(2), 533-541.

Kozimor, M. L. (2020). Editor's comment: Three teaching takeaways from the COVID-19 pandemic. Retrieved from: https://journals.sagepub.com/doi/full/10.1177/0092055X20931953

Lee, E., \& Hannafin, M. (2016). A design framework for enhancing engagement in student-centered learning: Own it, learn it, and share it. Education Technology Research Development, 64, 707-734.

Oberski, I., Ford, K., Higgins, S., \& Fisher, P. (1999). The importance of relationships in teacher education. Journal of Education for Teaching, 25(2), 135-150. https://doi.org/10.1080/02607479919600.

Ryan, R. M., \& Deci, E. L. (2000). Self-determination theory and the facilitation of intrinsic motivation, social development, and well-being. American Psychologist, 55(1), 68.

Schneider, S., Nebel, S., Beege, M., \& Rey, G. (2018). The autonomy-enhancing effects of choice on cognitive load, motivation and learning with digital media. Learning and Instruction, 58, 161-172.

Weiner, C. (2003). Key ingredients to online learning: Adolescent students study in cyberspace - The nature of the study. International Journal on E-Learning, 2(3), 44-50 Norfolk, VA: Association for the Advancement of computing in education (AACE).

Publisher's Note Springer Nature remains neutral with regard to jurisdictional claims in published maps and institutional affiliations.

Dr. Joshua Tabor is an Adjunct Pprofessor in the University of North Texas College of Education and a digital learning specialist in Denton Independent School District. He has conducted research on effective online learning at the secondary level and investigated blended learning methods in public school districts. He was a research fellow with the Learning Accelerator where he studied the implementation of a blended learning model on a large suburban school district and presented his findings at the Aurora Institute. Dr. Tabor has been published in the International Journal of Education in Mathematics, Science and Technology and has helped edit books on structuring blended learning in the classroom. 